\title{
Surface and grain boundary analysis of doped zirconia ceramics studied by AES and XPS
}

\author{
G. S. A. M. THEUNISSEN, A. J. A. WINNUBST*, A. J. BURGgRAAF \\ University of Twente, Faculty of Chemical Technology, Lab. for Inorganic Chemistry, Materials \\ Science and Catalysis, PO Box 217, 7500 AE Enschede, The Netherlands
}

The surface- and grain boundary composition of $Y, C e$ and Ti doped zirconia were studied by $\mathrm{X}$-ray Photoelectron Spectroscopy and Auger Electron Spectroscopy/Scanning Auger Microscopy. The grain boundaries and free surfaces showed the same enrichment levels. After heat treatment $\geq 1000^{\circ} \mathrm{C}$ all yttria doped samples showed yttrium enrichment. In the $\mathrm{ZrO}_{2}-\mathrm{Y}_{2} \mathrm{O}_{3}$ system the yttrium enrichment did not depend on the bulk concentration and amounted $30-34 \mathrm{~mol} \% \mathrm{YO}_{1.5}$ in all cases. As a consequence the segregation factor increases with decreasing solute concentration in the bulk. The thickness of the segregation layer was about 2-4 $\mathrm{nm}$. In the ternary $Y$ doped systems yttrium is the main segregant. In ceria-doped tetragonal zirconia polycrystals ( $\mathrm{Ce}-\mathrm{TZP}$ ) systems significant segregation of cerium starts at $T \geq 1300^{\circ} \mathrm{C}$ and is mainly attributed to $\mathrm{Ce}^{3+}$. In Y,Ti-TZP systems also strong segregation of $\mathrm{Ti}^{4+}$ occurs. The absolute value of the increase of the surface concentration in fine grained material is smaller than in coarse grained material. This is mainly due to depletion of the bulk.

\section{Introduction and theory}

It is widely recognized that the mechanical and electrical properties of ceramics can be influenced to a large extent by the composition or stability of the grain boundaries. In solid solutions differences are often present in chemical composition between the bulk and grain boundaries or interfaces due to the presence of impurities which can segregate preferentially to the interfaces. This is of great importance in ceramic processing because it can control sintering and grain growth to a large extent [1]. Besides this, segregation of main components may decrease the electrical conductivity $[2,3]$ or influence the thermal stability of tetragonal zirconia in humid environments [4].

Today some calculations have been made about surface coverages (or segregation levels) of various dopants in ceramic materials like $\mathrm{Al}_{2} \mathrm{O}_{3}$ and $\mathrm{NiO}$ $[5,6]$. However, despite its considerable importance, few data have been presented of doped zirconia systems and in particular of tetragonal zirconia.

Several reasons might exist for dopants to segregate to the interfaces [7]. The most important mechanisms for segregation in doped zirconia materials are (i) strain energy (relaxation) and; (ii) electrostatic potential and charge compensation.

(i) strain relaxation

For equilibrium segregation, McLean [8] gave the following expression:

$$
\frac{X_{\mathrm{b}}}{X_{\mathrm{bo}}-X_{\mathrm{b}}}=\frac{X_{\mathrm{c}}}{1-X_{\mathrm{c}}} \exp \left(\frac{-E_{1}}{R T}\right)
$$

with $X_{\mathrm{bo}}$ and $X_{\mathrm{b}}$ the saturation and actual value of the fractional concentration at the grain boundary, respectively, $X_{\mathrm{c}}$ the (fractional) bulk concentration of the dopant and $E_{1}$ the energy of adsorption. $R T$ has its usual meaning. The energy of adsorption can obtain an important contribution from a size mismatch between atoms (ions) of the solute and the matrix of the solvent. This contribution is given by

$$
E_{1}=\frac{24 K G r_{1} r_{2}\left(r_{2}-r_{1}\right)^{2}}{4 G r_{1}+3 K r_{2}}
$$

with $K$ and $G$ the bulk and shear modulus of the matrix, respectively and $r_{1}$ and $r_{2}$ the effective radii of the solvent and solute atoms. So $E_{1} \propto \varepsilon^{2}$ with $\varepsilon=\left(r_{1}\right.$ $\left.-r_{2}\right) / r_{1}$ (where $\varepsilon$ is the misfit value). Especially when $\varepsilon>0.2$ this mechanism will become important. For smaller misfit values and if the segregant cation has a valency which is different from the bulk (solvent) cations the formation of charged interfaces becomes important as an additional driving force for segregation. Equation 1 however applies only to diluted systems. In a model for concentrated systems [9] the enrichment ratio $\beta_{\mathrm{b}}$ of the grain boundary is described by

$$
\frac{X_{\mathrm{b}}}{X_{\mathrm{bo}}} \frac{1}{X_{\mathrm{c}}}=\beta_{\mathrm{b}}=\frac{f}{X_{\mathrm{Co}}}
$$

with $X_{\mathrm{Co}}$ the fractional saturation solubility in the bulk and $f$ a constant between 1 and 10. From this it can be seen that $\beta_{\mathrm{b}}$ increases with decreasing solubility. 
(ii) Electrostatic potential.

Since $g_{+} \neq g_{-}\left(g_{+}\right.$and $g_{-}$are the intrinsic energies of formation of cation and anion vacancies, respectively) there will be an excess of the defect with the smaller gvalue at the surface which results in a boundary charge. Between the interface and bulk a space charge region exist which is characterized by the Debye length $L_{\mathrm{d}}$

$$
L_{\mathrm{d}}=\left[\frac{\varepsilon_{\mathrm{d}}}{8 \pi} \frac{k T}{q^{2} n}\right]^{1 / 2}
$$

with $\varepsilon_{\mathrm{d}}$ the dielectrical constant, $q$ the charge, $n$ the concentration of charged species at a large distance from the interface and where $k T$ has its usual meaning. In insulators: $L_{\mathrm{d}} \approx 2-10 \mathrm{~nm}$. In oxides we normally have an extrinsic situation (impurities) which gives a relatively large concentration of aliovalent solute ions compared to the thermally generated concentration of vacancies.

Estimates of the contribution of the several mechanisms in metal oxide ceramics indicate that the strain relaxation term is the most important one, especially for specimens treated at high temperatures where electrostatic contributions may be neglected [7]. Nevertheless, when aliovalent dopants are present and the misfit is not too big, the space charge contribution can be considerable. For zirconia ceramics doped with $\mathrm{Y}^{3+}$ and $\mathrm{Ti}^{4+}$ the misfit is bigger than $0.20(0.21$ and -0.28 , respectively [10]) whereas the misfit with $\mathrm{Ce}^{4+}$ is smaller (0.15). However the misfit of $\mathrm{Ce}^{3+}$ is much bigger (0.36) and moreover there are charge differences present between $\mathrm{Y}^{3+}, \mathrm{Ce}^{3+}$ and $\mathrm{Zr}^{4+}$.

From Equation 1 it can be seen that in most cases the degree of segregation under equilibrium conditions will increase as the temperature is lowered or the dopant concentration increases. Although, in general, segregation is a combination of equilibrium and nonequilibrium segregation Waite [11] showed that equilibrium conditions can be expected after an annealing treatment (for several hours) at $1000^{\circ} \mathrm{C}$. After the annealing treatment very fast cooling is required to freeze this high temperature "equilibrium" situation.

Although segregation to grain boundaries might differ from that to surfaces, in ceramic materials the correlation factor between grain boundary and surface segregation seems to be close to unity [7]. As the method to analyse grain boundaries is rather time consuming, in general surface segregation measurements will be used and measurement of grain boundaries will only be done incidentally.

In order to find an explanation for observed grain growth differences in doped zirconia materials [12, 13] the surface and grain boundaries of these materials were investigated by means of Auger electron spectroscopy (AES) and X-ray photoelectron spectroscopy (XPS).

\section{Experimental procedure}

\subsection{Sample preparation}

Zirconia powders with an overall composition $\left(\mathrm{ZrO}_{2}\right)_{100-x}\left(\mathrm{YO}_{1.5}\right)_{x}, \quad$ (code: $\left.\mathrm{ZYX}\right) ; \quad\left(\mathrm{ZrO}_{2}\right)_{100-y}$ $\left(\mathrm{CeO}_{2}\right)_{y}$, (code: $\left.\mathrm{ZCeY}\right) ; \quad\left(\mathrm{ZrO}_{2}\right)_{100-x-y}$
$\left(\mathrm{YO}_{1.5}\right)_{x}\left(\mathrm{CeO}_{2}\right)_{y}$, (code: $\left.\mathrm{ZY}_{x} \mathrm{Ce}_{y}\right)$ and $\left(\mathrm{ZrO}_{2}\right)_{100-x-z}$ $\left(\mathrm{YO}_{1.5}\right)_{x}\left(\mathrm{TiO}_{2}\right)_{z}$, (code: $\left.\mathrm{ZY}_{x} \mathrm{Ti}_{z}\right)$ were prepared by gelprecipitation starting from metal chlorides or alkoxides $[14,15]$. The powders were isostatically pressed at $400 \mathrm{MPa}$ and sintered at temperatures ranging from $1000-1400^{\circ} \mathrm{C}$. Generally, dense samples with a relative density of more than $95 \%$ and a grain size larger than $0.1 \mu \mathrm{m}$ were obtained.

The following procedure was adapted for all samples unless stated otherwise. Before the surface analysis experiments were carried out, the specimens were polished with $0.3 \mu \mathrm{m} \quad \mathrm{Al}_{2} \mathrm{O}_{3}$ and ultrasonically cleaned in ethanol. After this, the specimens were submitted to a heat treatment $600-1400^{\circ} \mathrm{C}$, quenched to room temperature and stored in a desiccator. As a standard, coarse grained and dense rods were prepared which fractured transgranularly under ultrahigh vacuum conditions. In this way surface contamination could be avoided and a fresh surface having the bulk composition was obtained. In the Y-TZP, Y,Ce-TZP and Y,Ti-TZP materials intergranular fracture was obtained when using fine grained ceramics (i.e. grain size less than $0.3 \mu \mathrm{m}$ ). Intergranular fracture could also be obtained by fracturing materials with a relative density of about $80 \%$ [3]. In the Ce-TZP materials, intergranular fracture surfaces were obtained by cycling the material a few times through the monoclinic-tetragonal phase transition.

\subsection{Methods of analysis}

Auger (AES) experiments were performed with a cylindrical mirror analyser, type 10-155 (Physical Electronics) with a beam diameter of about $100 \mu \mathrm{m}$, a primary beam current of $0.25 \mu \mathrm{A}$ and a primary beam energy of $3 \mathrm{keV}$. No sample charging occurred under these conditions when clean specimens were used. The argon ion beam used for the sputtering experiments had an energy of $2 \mathrm{keV}$ and a beam current of about $30 \mu \mathrm{A} \mathrm{cm}^{-2}$.

Scanning Auger measurements (SAM) were performed with a PHI 600 SAM system. The analysed area was about $0.5 \mu \mathrm{m}^{2}$ (beam diameter $0.7 \mu \mathrm{m}$ ) at a primary beam energy $E_{\mathrm{p}}=3 \mathrm{keV}$ and a beam current $I_{\mathrm{p}}=0.1 \mu \mathrm{A}$. The resolution of the cylindrical mirror analyser was set at $0.6 \%$. Alternate sputtering and Auger analysis were used during in-depth analysis. The argon ion beam with an ion energy of $3.5 \mathrm{keV}$ was produced by a differentially pumped ion gun.

In case of AES the spectra were examined in a semiquantitative way using the equation of Palmberg et al. $[16]$

$$
\left[C_{x}=\frac{\left[I_{\mathrm{x}} / S_{\mathrm{x}}\right]}{\sum_{\alpha}\left[I_{\alpha} / S_{\alpha}\right]}\right]
$$

with $C$ the concentration (in at \%), I the peak intensity and $S$ the relative elemental sensitivity factor for the Auger line used. The subscripts $\mathrm{x}$ and $\alpha$ represent element $x$ and the sum of all the elements involved in the quantification, respectively. The yttrium and zirconium sensitivity factors were obtained from standard spectra (with transgranular fracture surfaces [3, 
17]), giving the oxygen sensitivity factor a fixed value [18]. The cerium and titanium sensitivity factors were obtained from Palmberg [16]. More details concerning the method of analysis can be found in References 3 and 18 .

For quantification the yttrium MNN $(76 \mathrm{eV})$, the zirconium MNN $(147 \mathrm{eV})$ and the oxygen KLL $(503 \mathrm{eV})$ Auger peaks are used. As in some cases a small amount of silica (which segregates quite easily) is present and the silicon LMM peak has the same kinetic energy as the yttrium peak $(76 \mathrm{eV})$ special attention is paid to silicon. The intensity of the silicon peak at $76 \mathrm{eV}\left(I_{\mathrm{Si}, 76}\right)$ can be derived from the intensity of the free KLL silicon peak at $1606 \mathrm{eV}$ (oxide form; in elemental form the peak is situated at $1619 \mathrm{eV}$ [16]). Using the sensitivity factors calculated from the standard $\mathrm{SiO}_{2}$ Auger spectrum [16] the derivation is performed as follows:

$$
\left[I_{\mathrm{Si}, 76}=\frac{I_{\mathrm{Si}, 1606} S_{\mathrm{Si}, 76}}{S_{\mathrm{Si}, 1606}}\right]
$$

The yttrium intensity $\left(I_{\mathrm{Y}}\right)$ is obtained by subtracting the silicon intensity from the total measured intensity at $76 \mathrm{eV}$ (under the assumption of symmetric peaks). Because only the upper part of the Auger peak at $76 \mathrm{eV}$ has been taken into account $[3,18], I_{\mathrm{Si}, 76}$ has to be divided by a factor of two to obtain the real yttrium intensity

$$
I_{\mathrm{Y}}=I_{\mathrm{tot}, 76}-1 / 2 I_{\mathrm{Si}, 76}
$$

in which $I_{\text {tot } 76}$ represents the measured half peak height at $76 \mathrm{eV}$.

XPS measurements were performed with a Kratos ES 200B spectrometer (Al- $K_{\alpha 1,2}$ radiation) and a Kratos XSAM-800 apparatus using both Al- $K_{\alpha 1,2}$ $(1487 \mathrm{eV})$ and $\mathrm{Mg}-K_{\alpha, 2}(1253.6 \mathrm{eV})$ radiation in a vacuum chamber operating at a pressure lower than 7 $\times 10^{-10}$ torr. The analysed area was about $0.2 \mathrm{~mm}^{2}$. The emitted electrons were collected and energy analysed in a concentric hemisphere analyser (CHA) located perpendicular to the sample surface. The energy resolution, defined as the full width at half maximum (FWHM), of the CHA amounted to $0.99 \mathrm{eV}$ at a pass energy of $20 \mathrm{eV}$. A $3 \mathrm{keV} \mathrm{Ar}{ }^{+}$ion beam was used during sputtering. The instrument was calibrated using the $\mathrm{Cu} 2 \mathrm{p} 3 / 2, \mathrm{Cu} 3 \mathrm{p} 3 / 2$ and $\mathrm{Cu}\left(\mathrm{L}_{3} \mathrm{M}_{5} \mathrm{M}_{5}\right)$ lines as a reference. Charge corrections were made using the free $\mathrm{C} 1 \mathrm{~s}$ signal $(285.1 \mathrm{eV})$ as a reference. In case of absence of the $\mathrm{C} 1 \mathrm{~s}$ peak, the $\mathrm{Zr} 3 \mathrm{~d} 5 / 2$ peak with a binding energy (BE) of $182.2 \mathrm{eV}$ (in accordance with the results of Hughes [19]) was chosen as a reference. For chemical state identification, quantitative analysis and peak deconvolution, detail scans were run. The peaks were deconvoluted assuming Gaussian profiles according to the method described by Sherwood [20]. In order to obtain good counting statistics, clear spectra and low noise levels multiple scannings were performed on every sample.

An equation similar to Equation 5 was used to quantify the XPS measurements [21]. The sensitivity factors were supplied by Kratos and are in good agreement with the sensitivity factors which were derived from standard rods (transgranular fracture surfaces).

Angle resolved XPS measurements were performed to measure the segregation levels as a function of the distance to the surface. The surface sensitivity was enhanced when low angles of electron exit, $\alpha$, to the surfaces were used [22]. The vertical depth sampled, $d$, is maximal when $\alpha=90^{\circ}$ and is given by

$$
[d=3 \lambda \sin \alpha]
$$

An Hitachi S-600 scanning electron microscope (SEM) was used for direct observations of the fracture surfaces.

\section{Results and discussion}

\subsection{Y-TZP}

To see whether the surface and grain boundary segregation levels were similar Y-TZP, Y, Ce-TZP, Y,Ti-TZP and Ce-TZP samples were fractured intergranularly. Two typical fracture surfaces are shown in Fig. 1. As can be seen from the rough surface and clearly visible grain boundaries both fracture surfaces show nearly $100 \%$ intergranular fracture. For all systems the grain boundary concentration was in all cases nearly identical to the surface concentration. It could be concluded that the measured surface concentration in these systems after a heat treatment $\geq 1000^{\circ} \mathrm{C}$ gives a good approximation of the grain boundary concentration.

An Auger spectrum of a polished surface of ZY17 which is not-treated and heat treated at $1000^{\circ} \mathrm{C}$, is shown in Fig. 2a and b, respectively. It can be seen that the $\mathrm{Y} / \mathrm{Zr}$ peak intensity ratio of the temperature treated specimen (Fig. 2b) is higher than that of the nontreated (Fig. 2a). The inaccuracy in the choice of the baseline is smaller than the observed differences in the peak intensity ratio between the two spectra. Therefore, it can be concluded that yttrium enrichment occurs at the surface of $\mathrm{ZY} 17$.

The yttrium enrichment at the surface is also indicated by a decrease of the yttrium signal as function of the $\mathrm{Ar}^{+}$ion-sputtering time. No preferential sputtering of yttrium or zirconium was observed, as was also shown by Winnubst et al. [3]. After 30 to $40 \mathrm{~s}$ of $\mathrm{Ar}^{+}$ion sputtering the $\mathrm{Y} / \mathrm{Zr}$ peak intensity ratio becomes constant. The thickness of the segregation layer can not be determined with any precision because some reduction of $\mathrm{Zr}^{4+}$ to zirconium metal may occur (both peaks do not have the same kinetic energy) and the not exactly known sputter rate, but is estimated to be about 2 to $4 \mathrm{~nm}$. The (XPS) sputter profile of a ZY5 single crystal is shown in Fig. 3. The surface concentration equals the bulk concentration after about $8-10 \mathrm{~min}$ of sputtering. Assuming a sputter rate of about $0.5 \mathrm{~nm} \mathrm{~min}^{-1}$ [23] the thickness of the segregation layer is estimated to be $4 \mathrm{~nm}$ which compares rather well with the AES results obtained by Winnubst et al. [3]. When sputtering polycrystalline material the measured surface concentration is higher than the initial bulk concentration even after longer times of sputtering. A surface composition of ZY9 is found in a ZY5 sample after $10 \mathrm{~min}$ of sputtering. The 

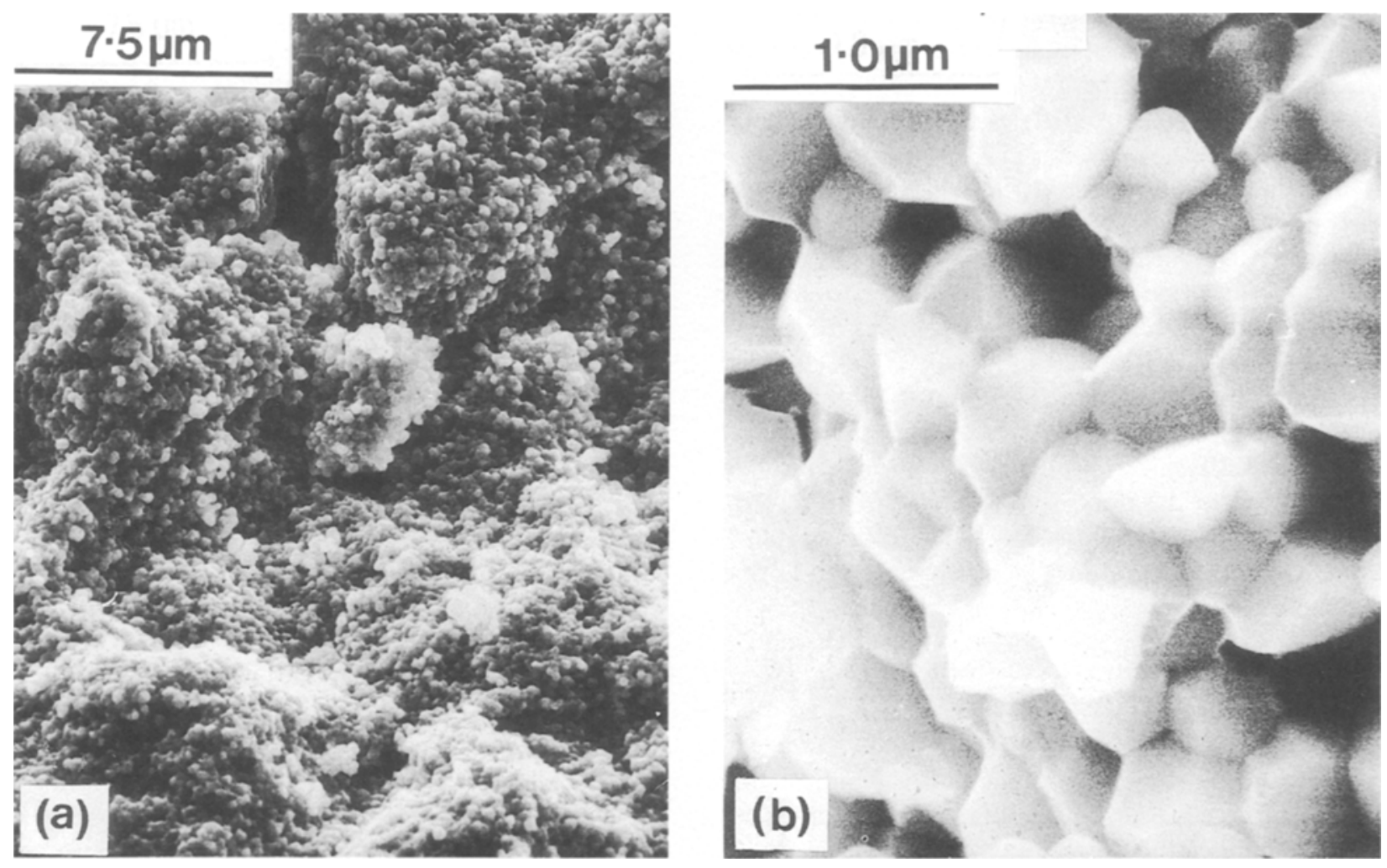

Figure I Fracture surfaces showing mainly intergranular fracture (a) ZCe9; (b) ZY3Ti13.

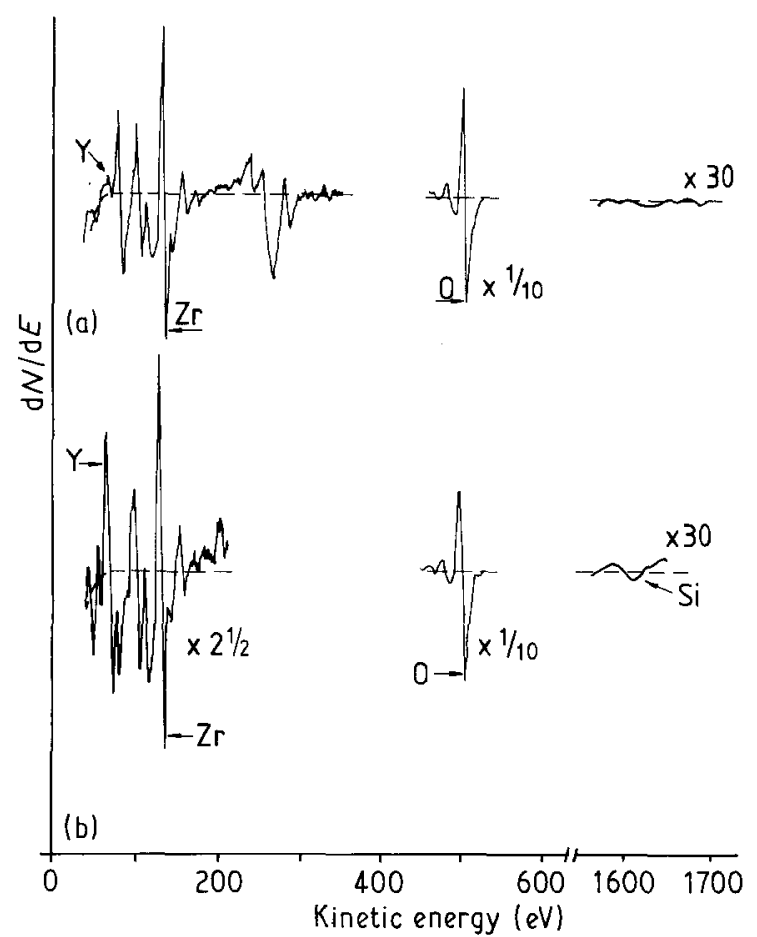

Figure 2 Auger spectra of polished ZY17 surfaces (a) non-treated (b) treated for $5 \mathrm{~h}$ at $1000^{\circ} \mathrm{C}$. The numbers $2.5,0.1$ and 30 denote the enlargement factor of the relevant parts of the figure.

same has been observed in ternary systems (a surface composition of ZY13Ti5 in a ZY5Ti5 sample after $30 \mathrm{~min}$ of sputtering). This effect is attributed to the surface roughness of the polycrystalline materials which increases during sputtering and which causes averaging of the concentration over areas with different composition.

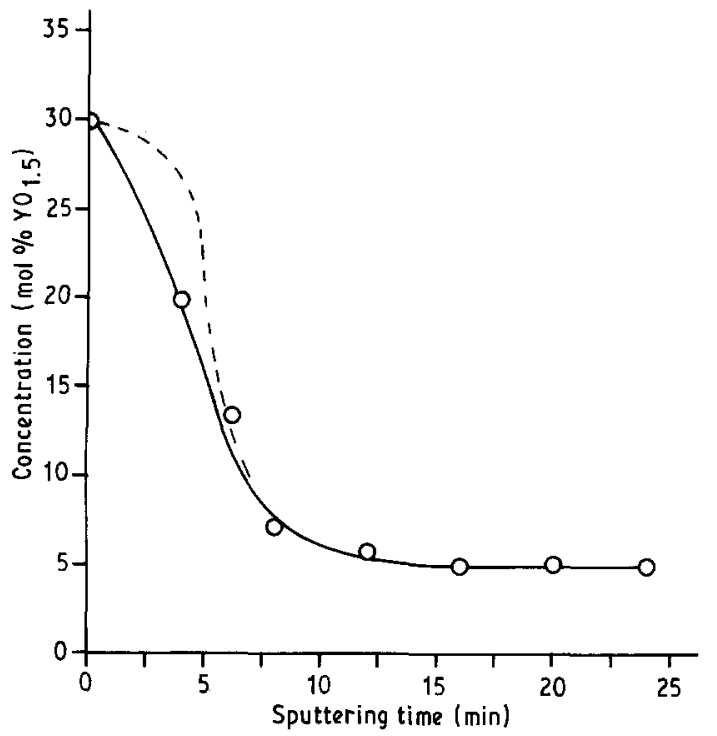

Figure $3 \mathrm{Ar}^{+}$sputter profile of a ZY5 single crystal as measured by XPS. Heat treatment: $1000^{\circ} \mathrm{C}$ for $2 \mathrm{~h}$. The dashed line represents the expected profile.

The quantitative results of the measurements (for $\mathrm{ZY}_{x}$ compositions) are given in Table I. It can be seen that after a heat treatment at $1000^{\circ} \mathrm{C}$ a pronounced yttrium enrichment takes place up to about 30-34 mol\% $\mathrm{YO}_{1.5}$ (these results are already corrected for possible silicon contamination if present).

In a sample deliberately contaminated with about $0.5-1 \mathrm{wt} \% \mathrm{SiO}_{2}$ the real peak intensity of yttrium was about $20 \%$ lower than for the case where the total $76 \mathrm{eV}$ peak intensity was ascribed to yttrium. Ignoring silicon a composition of $\mathrm{ZY} 42$ was calculated whereas ZY34 was calculated with silicon taken into account. 
TABLE I Surface composition of $\mathrm{ZrO}_{2}-\mathrm{Y}_{2} \mathrm{O}_{3}$ ceramics heat treated for $5 \mathrm{~h}$ as determined by AES (materials with compositions between 4 and $9 \mathrm{~mol} \% \mathrm{YO}_{1.5}$ have a tetragonal structure, the others have a cubic (fluorite) structure)

\begin{tabular}{lcc}
\hline $\begin{array}{l}\text { Bulk concentration } \\
\left(\mathrm{mol}_{\mathrm{YO}} \mathrm{YO}_{1.5}\right)\end{array}$ & $\begin{array}{c}\text { Temperature } \\
\text { treatment }\left({ }^{\circ} \mathrm{C}\right)\end{array}$ & $\begin{array}{l}\text { Surface concentration } \\
\left(\mathrm{mol} \% \mathrm{YO}_{1.5}\right)\end{array}$ \\
\hline 4 & 600 & 5 \\
4 & 1000 & 31 \\
$5^{*}$ & 600 & 6 \\
$5^{*}$ & 1000 & 30 \\
6.1 & 600 & 6 \\
6.1 & 700 & 14 \\
6.1 & 1000 & 30 \\
8.9 & 1000 & 29 \\
13 & 600 & 11 \\
13 & 700 & 12 \\
13 & 1000 & 34 \\
17 & 600 & 17 \\
17 & 1000 & 35 \\
$17^{*}$ & 1000 & 31 \\
26.4 & 600 & 28 \\
26.4 & 1000 & 34 \\
32 & 600 & 33 \\
\hline
\end{tabular}

* Single crystals

In this case 3 at $\%$ silicon was found at the surface.

The fact that the increased intensity of the $76 \mathrm{eV}$ peak after heat treatment is not due to silicon is better illustrated with XPS where the silicon and yttrium peaks are well separated. In the XPS spectrum shown in Fig. $4 \mathrm{a}$, performed on a sample with a Si contamination $<0.05 \mathrm{wt} \%$ no significant amount of silicon seemed to be present (the binding energy of the Si2s peak is $153 \mathrm{eV}$ [21]. The detection limit is about $0.2 \mathrm{at} \%$ ). The XPS spectrum of a contaminated sample is shown in Fig. 4 b. There the silicon peak is clearly visible.

In the XPS spectra yttrium enrichment is also observed after heat treatment. A surface composition of ZY28 is calculated (bulk composition ZY6.1). This value is close to a concentration of about $30 \mathrm{at} \%$ yttrium as measured by Hughes [19] with XPS on a mainly intergranular fracture surface of a ZY19 sample. The results were also confirmed by Steele and Butler [24], who found with XPS a concentration of 33 at \% yttrium on the $(001)$ surface of ZY15.

So in conclusion one can say that all samples which were heat treated at $1000^{\circ} \mathrm{C}$ showed an yttrium enrichment of the surface to a concentration of $30-34$ at $\%$ (and as indicated before, the same concentration will be found in the grain boundary $[3,7,25])$. The yttrium enrichment is independent of the crystal structure (both 100\% tetragonal and 100\% cubic materials show the same result) and bulk composition. Hence this concentration seems to be a saturation value. Stubican [26] reported a stable phase with a composition of $40 \mathrm{~mol} \% \mathrm{YO}_{1.5}$ which suggests the possibility of a surface phase. If one keeps in mind that ZY34 is an average value over a range of some nanometres (the information depth is a few nanometres) it is possible that the real surface concentration is somewhat higher. However when low angles of electron exit ( $\left.\alpha=10^{\circ}\right)$ were used, no higher segrega-

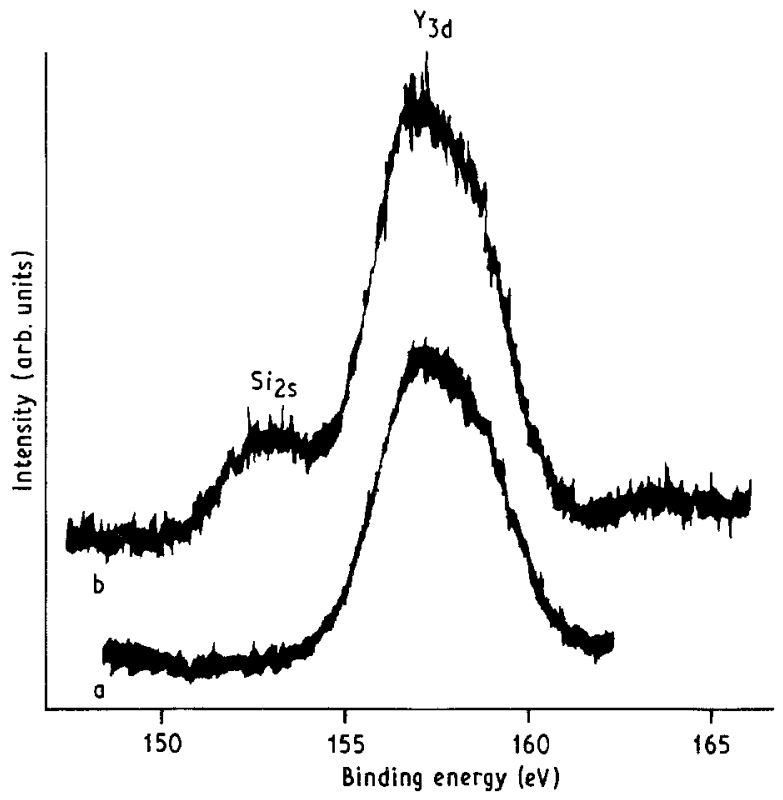

Figure 4 XPS spectra of ZY specimen heat treated at $1000^{\circ} \mathrm{C}$ for 5 h: (a) ZY6.1 without Si contamination; (b) ZY4 with Si contamination (about $0.5-1 \mathrm{wt} \% \mathrm{Si}$ ).

tion levels were detected. Probably the surface concentration is constant in the first few nanometres.

The grain size might influence the results of the measurements (section 3.4). Because coarse grained $(>0.1 \mu \mathrm{m})$ and polished materials are used, in this case this effect is thought to be unimportant.

The impact of the segregation behaviour of yttrium in zirconia is that the enrichment factor $\beta$ (defined as $C_{\text {surface }} / C_{\text {bulk }}$ ) for materials containing low amounts of yttria (i.e. tetragonal materials) is much larger than for the (cubic) materials containing high percentages of yttria. This might result in a stronger "solute" drag during grain growth for zirconia ceramics doped with low amounts of yttria. This is outlined in more detail in Reference 35.

\subsection{Ce-TZP and $Y, \mathrm{Ce}-\mathrm{TZP}$}

The cerium containing samples are difficult to quantify with AES due to strong overlap of the cerium peak with other zirconium and yttrium peaks in the low kinetic energy range between 60 and $100 \mathrm{eV}$, whereas the sensitivity of the high energy cerium peak is rather weak to give clear peaks. Thus only in the case of large enrichment of the surface some attempts have been made to obtain quantitative results (Table II). Only after a heat treatment at $1400^{\circ} \mathrm{C}$ the surface was clearly enriched in cerium.

XPS measurements were performed due to the difficulties mentioned above and in order to get information on the oxidation state of cerium. This is complicated by the presence of shake-up satellite lines in the XPS spectra which may approach that of the main line as is especially the case for the Ce3d line.

The results for $\mathrm{Ce}-\mathrm{TZP}$ and $\mathrm{Y}, \mathrm{Ce}-\mathrm{TZP}$ are presented in Tables II and III, respectively. The Ce-TZP surfaces are hardly enriched in cerium up to about 
TABLE II SAM and XPS measurements on surfaces of Ce-TZP ceramics. No heat treatment has been applied after non-isothermal sintering. The fraction $\mathrm{Ce}^{3+}$ is given as the fraction of the total amount cerium present at the surface.

\begin{tabular}{llllll}
\hline Bulk composition & Method & $T\left({ }^{\circ} \mathrm{C}\right)$ & $\rho_{\text {rel }}(\%)$ & \multicolumn{2}{c}{ Surface composition* Fract. Ce ${ }^{3+}$} \\
\hline ZCe9 & XPS & 1000 & 60 & ZCe9 & ZCe9 \\
ZCe9 & XPS & 1100 & 85 & ZCe10 & 0.38 \\
ZCe9 & XPS & 1200 & 92 & ZCe14 & 0.46 \\
ZCe9 & XPS & 1300 & 96 & ZCe22 & 0.49 \\
ZCe9 & XPS & 1000 & 96 & ZCe13 & not analysed \\
ZCe9 & XPS & 600 & 96 & ZCe9 & \\
ZCe9 & SAM & 1300 & 96 & ZCe50 \\
ZCe9 & SAM & & 96 & & \\
\hline
\end{tabular}

* due to C-contamination, the surface was sputtered for $2 \mathrm{~min}$ to remove the C-layer.

\# heat treatment time of $7 \mathrm{~h}$, respectively.

TAB LE III XPS measurements on surfaces of Y,Ce-TZP ceramics heat treated for $2 \mathrm{~h}$.

\begin{tabular}{lll}
\hline $\begin{array}{l}\text { Bulk composition } \\
\left(\mathrm{ZY} \mathrm{Ce}_{y}\right)\end{array}$ & $\begin{array}{l}\text { Temperature } \\
\text { treatment }\left({ }^{\circ} \mathrm{C}\right)\end{array}$ & $\begin{array}{l}\text { Surface composition } \\
\left(\mathrm{ZY}_{x} \mathrm{Ce}_{y}\right)\end{array}$ \\
\hline $\mathrm{ZY4Ce} 2$ & 1000 & $\mathrm{ZY6Ce} 2$ \\
$\mathrm{ZY} 4 \mathrm{Ce} 4$ & 1000 & $\mathrm{ZY9Ce} 5$ \\
$\mathrm{ZY} 4 \mathrm{Ce} 10$ & 1000 & $\mathrm{ZY} 10 \mathrm{Ce} 10$ \\
$\mathrm{ZY} 3.5 \mathrm{Ce} 4.5$ & 1000 & $\mathrm{ZY7Ce} 5$ \\
$\mathrm{ZY4Ce} 2$ & 1400 & $\mathrm{ZY9Ce} 4$ \\
$\mathrm{ZY} 4 \mathrm{Ce} 4$ & 1400 & $\mathrm{ZY} 10 \mathrm{Ce} 6$ \\
\hline
\end{tabular}

$1200^{\circ} \mathrm{C}$. At higher temperatures clear enrichment occurs. In the Y,Ce-TZP samples (Table IV) yttrium segregates preferentially (with hardly any cerium enrichment) although the segregation level is much lower than in Y-TZP. The enrichment factor at $1000^{\circ} \mathrm{C}$ varies from 1.5 with low ceria content to 2.5 with high ceria content while for Y-TZP enrichment factors of about 7 are found (Table I). At $1400^{\circ} \mathrm{C}$ the enrichment of both yttrium and cerium is slightly increased. Compared to $\mathrm{Ce}-\mathrm{TZP}$ the segregation level of cerium is much lower in the Y,Ce-TZP systems. An explanation might be that yttrium is already present at the surface before segregation of cerium starts which reduces the driving force for cerium segregation.

Khan [27] performed XPS measurements on selected compositions in the zirconia rich corner of the $\mathrm{ZrO}_{2}-\mathrm{CeO}_{2}-\mathrm{Y}_{2} \mathrm{O}_{3}$ system. In the ceria poor compositions both cerium and yttrium were found to be present at the grain boundary, although ratios are not given. In the ceria rich compositions ( $>4 \mathrm{~mol} \%$ ) no yttrium was found at the grain boundary. However, their measuring time seems to be rather short (giving a bad signal/noise ratio). The enrichment factor for cerium ranges between 1-2 which seems also not so different from our results.

In Ce-TZP significant segregation starts at $1300^{\circ} \mathrm{C}$. A level of $22 \mathrm{~mol}^{\circ} \mathrm{CeO}_{2}$ is reached at $1400{ }^{\circ} \mathrm{C}$ (where cerium is both in the tetravalent and trivalent oxidation state). As is shown in Reference 13 this can be related to the grain growth behaviour of these ceramics. In some of the Ce-TZP ceramics the grain size distribution was very broad. Therefore both large and small grains were examined in one sample (SAM) to see whether the surface composition of large grains is different from that of small grains, but this was not found.
Longo [28] revealed the presence of a $\mathrm{Zr}-\mathrm{Ce}$ phase in the $\mathrm{ZrO}_{2}-\mathrm{CeO}_{2}$ phase diagram. This (tetragonal) phase was identified as $\mathrm{Ce}_{2} \mathrm{Zr}_{3} \mathrm{O}_{10}$ and was believed to be stable at temperatures below $870^{\circ} \mathrm{C}$. Although the estimated composition measured by SAM (Table II) is close to the composition of this phase, the XPS measurements clearly yielded lower enrichment levels.

In addition, percentages of the $\mathrm{Ce}^{3+}$ species were calculated relative to the total amount of cerium present (Table II) as TGA experiments [13] suggested the presence of a significant amount of $\mathrm{Ce}^{3+}$ above $1200^{\circ} \mathrm{C}$. The segregation tendency of $\mathrm{Ce}^{3+}$ is expected to be higher because of its larger misfit and difference in valency with respect to $\mathrm{Zr}^{4+}$. This might explain the increased enrichment at high temperatures. This is supported by the XPS measurements which show an increasing fraction $\mathrm{Ce}^{3+}$ with temperature (the fraction $\mathrm{Ce}^{3+}$ increased from about 0.38 at $1000^{\circ} \mathrm{C}$ to 0.51 at $1400^{\circ} \mathrm{C}$ (Table II)). The procedure of oxidation state determination is discussed below.

The binding energy of $\mathrm{Ce}^{4+}$ (Table IV) is lower than the binding energy of the Ce-metal species although the difference is not very large. This is rather strange because for all the other lanthanides the reverse is the case. No explanation has been found for this behaviour. The reported values for the binding energy of $\mathrm{Ce}^{3+}$ show a large variation (Table IV), one being lower and the other being higher than the binding energy of $\mathrm{Ce}^{4+}$. Because of the uncertainty in the exact line position of $\mathrm{Ce}^{3+}$ the position of the $\mathrm{Ce}^{3+} 3 \mathrm{~d} 5 / 2$ peak is evaluated by sputtering. During this process

TABLE IV Binding energies of Ce3d5/2 lines.

\begin{tabular}{lll}
\hline Oxidation state & BE $(\mathrm{eV})$ & Reference \\
\hline $\mathrm{Ce}$ & 883.2 & 29 \\
$\mathrm{Ce}(3+)$ & 883.9 & 30 \\
& 880.7 & 31 \\
& 885.8 & 29 \\
$\mathrm{Ce}(4+)$ & 886.0 & This work \\
& 881.8 & 21 \\
& 881.93 & 31 \\
& 882.2 & 32 \\
& $882.2^{*}$ & 33 \\
& 882.7 & 34 \\
\hline
\end{tabular}

* oxidation state uncertain. 
the oxygen ions are preferentially sputtered (indicated by a decrease in oxygen concentration). No preferential sputtering of $\mathrm{Ce}^{3+}$ or $\mathrm{Ce}^{4+}$ has been observed. The electrons which are left behind are taken up by cerium thus changing its oxidation state from $4+$ to $3+$. A Ce $3 \mathrm{~d}$ spectrum before and after sputtering is shown in Fig. 5. After sputtering the shape of the curve has clearly changed. The deconvoluted Ce3d spectra are shown in Fig. 6. The peaks at 889.6 and $888.6 \mathrm{eV}$ (Fig. 6a and 6b, respectively) can be regarded as satellite lines [23]. In accordance with Table IV the peak with the lowest binding energy (about $882.5 \mathrm{eV}$ in both figures) is designated as the $\mathrm{Ce}^{4+} 3 \mathrm{~d} 5 / 2$ peak. The binding energies found were in good agreement with the data of Sarma [34]. After sputtering, the relative

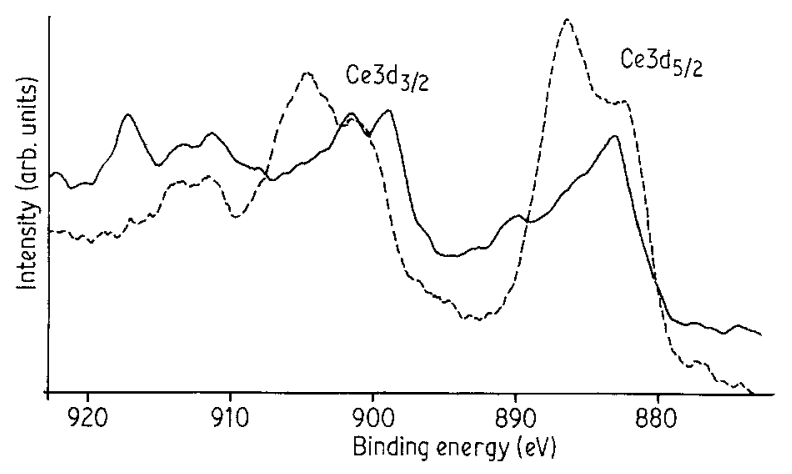

Figure 5 Ce3d XPS line spectra of a ZCe9 sample heat treated at $1000^{\circ} \mathrm{C}$ for $2 \mathrm{~h}$ before $(\longrightarrow)$ and after (-.) $10 \mathrm{~min}$ of $\pm 5 \mathrm{~nm}$ sputtering.
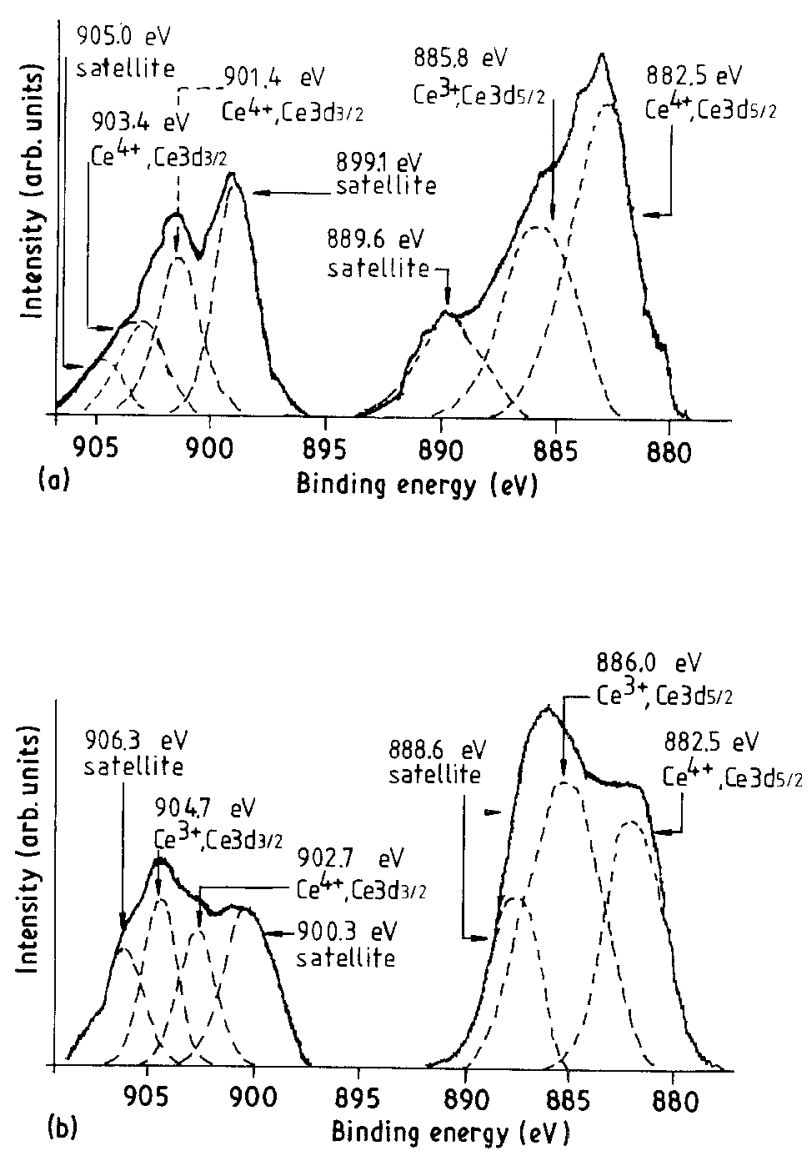

Figure 6 Deconvolution of the Ce3d core level spectra of a ZCe9 sample heat treated at $1000^{\circ} \mathrm{C}$ for $2 \mathrm{~h}$ (a) before sputtering (b) after 10 min of sputtering. area of this peak has clearly diminished whereas the relative area of the peak with a binding energy of $886 \mathrm{eV}$ has increased. Apparently this is the $\mathrm{Ce}^{3+} 3 \mathrm{~d} 5 / 2$ peak. The binding energy of this peak is in good agreement with the binding energy given by Praline [29]. It should be noted that the binding energy of this peak is higher than the binding energy of the $\mathrm{Ce}^{4+} 3 \mathrm{~d} 5 / 2$ peak. It is possible that the peak ascribed to $\mathrm{Ce}^{3+}$ is the peak of the Ce-metal species. However Wagner [21] and Briggs [22] pointed out that in that case the intensity of the satellite peak would not increase. Fig. $6 \mathrm{~b}$ clearly shows that the reverse is the case.

In summary: the binding energy of the $\mathrm{Ce}^{4+} 3 \mathrm{~d} 5 / 2$ peak is $882.5 \pm 0.2 \mathrm{eV}$ with an FWHM of $3.7 \pm 0.2 \mathrm{eV}$ whereas the $\mathrm{Ce}^{3+} 3 \mathrm{~d} 5 / 2$ peak is situated at 886.0 $\pm 0.2 \mathrm{eV}$ with an FWHM of $3.6 \pm 0.3 \mathrm{eV}$. Using these data it could be shown that already at $1000^{\circ} \mathrm{C}$ a significant fraction of $\mathrm{Ce}^{3+}$ is present at the surface. The fraction $\mathrm{Ce}^{3+}$ increases with temperature. This means that $\mathrm{Ce}^{3+}$ becomes a more powerful segregant than $\mathrm{Ce}^{4+}$ at high temperature.

\section{3. $Y, T i-T Z P$}

The SAM and XPS results are presented in Table V. AES gives higher titanium concentrations but lower yttrium concentrations which might be due to the small yttrium peak which is hardly visible above the background. Yttrium as well as titanium segregates to the surface although the surface is relatively more enriched in yttrium (with similar bulk concentrations). The surface is enriched in titanium with a factor of approximately two while yttrium is enriched with a factor 2-3 (not found with AES). The unchanged Y concentration and strongly enhanced $\mathrm{Ti}$ concentration in the ZY3Ti13 sample, as well as the high Ce concentration in ZCe9 (SAM, Table II) may suggest the formation of an "overcoat" layer mainly consisting of $\mathrm{Ti}$ or $\mathrm{Ce}$ oxide (or compound). This has been observed by Van Hassel et al. [23] in Ti ion implanted oxides.

Just like cerium, titanium has several oxidation states. In a similar way as for cerium, the trivalent species could be introduced by sputtering (no preferential sputtering of titanium has been observed). Fig. 7

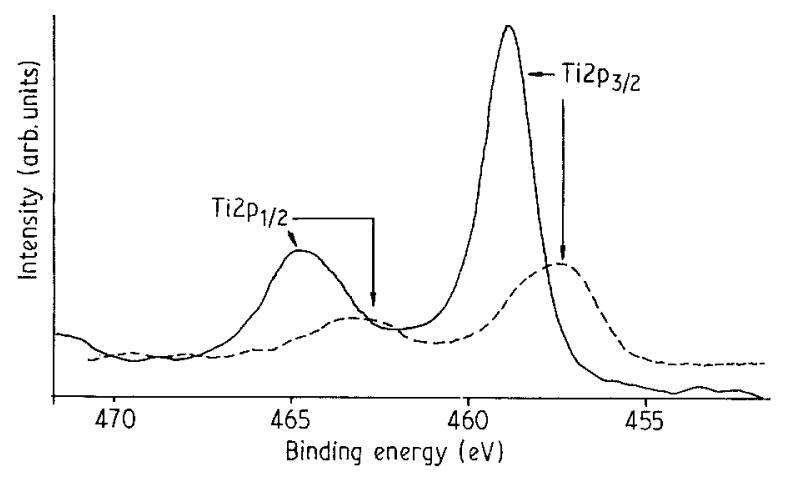

Figure 7 Ti2p core level spectra of a ZY5Ti5 sample heat treated at $1400^{\circ} \mathrm{C}$ for $2 \mathrm{~h}$ before ( $\longrightarrow$ ) and after (- . - ) $30 \mathrm{~min}$ of $\pm 15 \mathrm{~nm}$ sputtering. 
TABLE V XPS and SAM measurements on Y,Ti-TZP samples heat treated for $2 \mathrm{~h}$.

\begin{tabular}{llll}
\hline $\begin{array}{l}\text { Bulk composition } \\
\left(\mathrm{ZY}_{x} \mathrm{Ti}_{z}\right)\end{array}$ & Method & $\begin{array}{l}\text { Temperature } \\
\text { treatment }\left({ }^{\circ} \mathrm{C}\right)\end{array}$ & $\begin{array}{l}\text { Surface composition } \\
\left(\mathrm{ZY}_{x} \mathrm{Ti}_{z}\right)\end{array}$ \\
\hline ZY3Ti13* & XPS & 1300 & ZY7Ti25 \\
ZY5Ti5 & XPS & 600 & ZY4Ti5 \\
ZY5Ti5 & XPS & 1000 & ZY12Ti8 \\
ZY5Ti5 & XPS & 1400 & ZY18Ti11 \\
ZY5Ti5 & SAM & 1400 & ZY25Ti20 \\
ZY3Ti13* & SAM & 600 & ZY3Ti13 \\
ZY3Ti13* & SAM & 1300 & ZY2Ti30 \\
\hline
\end{tabular}

* received from Alusuisse Lonza, treatment time: $1 \mathrm{~h}$.

shows a Ti2p spectrum before and after sputtering. The deconvoluted spectra are presented in Fig. 8 using the binding energies of Table VI. Then the $\mathrm{Ti}^{3+} 2 \mathrm{p}$ peak becomes clearly visible. The binding energies of the Ti2p peaks are seen to agree very well with the literature data (Table VI).

After sputtering, about $55 \%$ of the Ti-species is in the trivalent oxidation state. In the non-sputtered sample no $\mathrm{Ti}^{3+}$ is present (Fig. 7a). This spectrum is representative for all the titanium spectra obtained. Therefore it can be concluded that all $\mathrm{Ti}$ in the samples used was in the tetravalent oxidation state.

\subsection{Segregation in fine grained materials}

Since in fine grained materials the total amount of yttrium present is not enough to provide for a concentration profile similar to that in coarse grained mater-
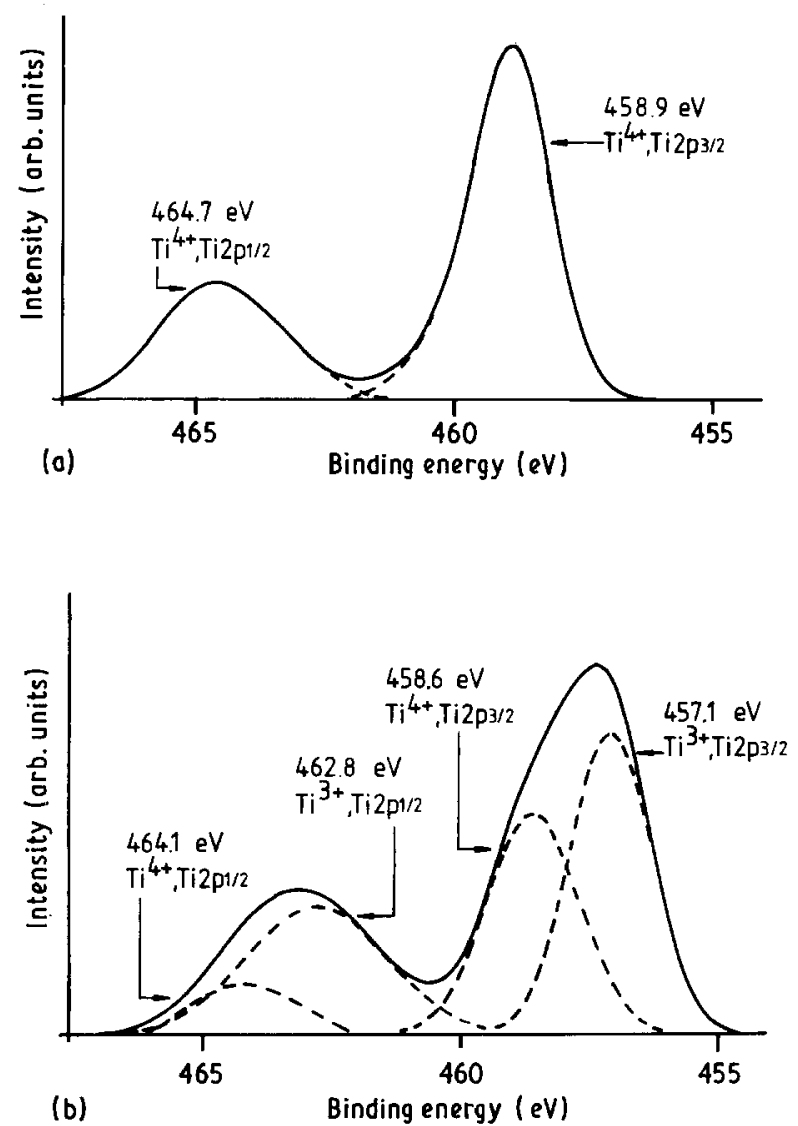

Figure 8 Deconvolution of the Ti2p core level spectra of a ZY5Ti5 sample heat treated at $1400^{\circ} \mathrm{C}$ for $2 \mathrm{~h}$, (a) before sputtering, (b) after $30 \mathrm{~min}$ of sputtering.
TABLE VI Binding energies of Ti2p lines.

\begin{tabular}{lll}
\hline Oxidation state & Peak & BE (eV) [23] \\
\hline $\mathrm{Ti}^{+}$ & $2 \mathrm{p} 3 / 2$ & 453.2 \\
$\mathrm{Ti}^{2+}$ & $2 \mathrm{p} 3 / 2$ & 455.3 \\
& $2 \mathrm{p} 1 / 2$ & 461 \\
$\mathrm{Ti}^{3+}$ & $2 \mathrm{p} 3 / 2$ & 457 \\
& $2 \mathrm{p} 1 / 2$ & 462.9 \\
$\mathrm{Ti4}^{+}$ & $2 \mathrm{p} 3 / 2$ & 458.5 \\
& $2 \mathrm{p} 1 / 2$ & 462.2 \\
\hline
\end{tabular}

ials this concentration profile will be different. Two situations may occur: (i) the thickness of the segregation layer remains the same during sintering while the bulk is completely depleted; (ii) the concentration changes gradually (requiring assumptions concerning the profile shape) with a distribution coefficient (segregation factor) which does not change and which is similar to the distribution coefficient in coarse grained material. The latter implies a lower surface as well as bulk concentration with respect to coarse grained material. Which situation represents the real situation is not clear but the last situation is thermodynamically more likely.

The question however remains how segregation measurements on fine grained material should be interpreted. It is not believed that porosity has much influence on the surface concentration although lower values might be measured owing to the rougher surfaces. Moreover the distribution coefficient and thickness of the segregation layer are generally not known. Measurement of the real surface concentration is more complicated by the fact that the information depth is equal to or somewhat larger than the expected thickness of the segregation layer. This gives an averaged result and hence a lower measured surface concentration.

An example is given in Fig. 9 where the surface concentration of a ZY5 sample is given as a function of the grain size. All (unpolished) samples were heat treated during $10 \mathrm{~min}$ at temperatures above $1000^{\circ} \mathrm{C}$ ). The surface concentration increases with increasing grain size. With a relatively large thickness of the segregation layer $(1.5-2 \mathrm{~nm})$ it can be calculated that a similar concentration profile to that in coarse grained material can be expected at a grain size between 50-100 nm [35]. More information and calculations about various situations and grain sizes which satisfy certain conditions can be found in Reference 35 . As the temperature was high enough for segregation and no 


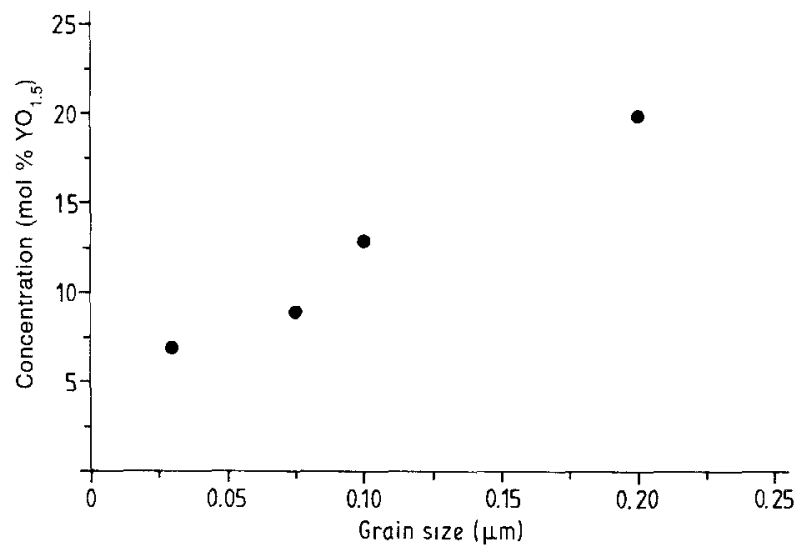

Figure 9 Surface concentration in (porous) Y-TZP ceramics as a function of the grain size. No heat treatment has been applied after non-isothermal sintering from $1000-1300^{\circ} \mathrm{C}$. The samples heat treated at 1000 and $1100^{\circ} \mathrm{C}$ were 65 and $90 \%$ dense, respectively. The other samples were more than $95 \%$ dense.

ZY34 is measured on the surfaces of the sample with a grain size smaller than $0.1 \mu \mathrm{m}$ a considerable amount of yttrium should be present in the bulk. This means that the most likely situation in fine grained materials is a situation with a smaller thickness of the segregation layer and a lower surface concentration (as well as a lower bulk concentration). Therefore with XPS and SAM precise information about surface compositions will only be obtained on relatively coarse grained material (grain size larger than about $0.10 \mu \mathrm{m}$ ). Measurements on fine grained material only give a qualitative picture.

\section{Conclusions}

1. In doped zirconia intergranular fracture surfaces (i.e. grain boundaries) and free surfaces show a similar segregation behaviour.

2. Sputtering of a heat treated ZY5 single crystal showed that the thickness of the segregation layer is maximally $2-4 \mathrm{~nm}$.

3. After a $5 \mathrm{~h}$ heat treatment at $1000^{\circ} \mathrm{C}, \mathrm{ZrO}_{2}-\mathrm{Y}_{2} \mathrm{O}_{3}$ ceramics contain about 30-34 at \% yttrium at their surface, regardless of the bulk composition of the ceramic.

4. 30 at $\%$ yttrium at the surface of ceramics containing low amounts of yttria (in the bulk) gives a larger yttrium enrichment factor than in ceramics containing larger amounts of yttria. The yttrium enrichment factor therefore increases from 1.5 to 7 with a bulk concentration of yttria decreasing from 26 to $4 \mathrm{~mol} \% \mathrm{YO}_{1.5}$.

5. Low angle XPS measurements provided similar segregation levels to those from the high angle measurements suggesting that the solute concentration remained constant over the information depth $(2-4 \mathrm{~nm})$.

6. To obtain reliable results for the quantification of $Y$ (with AES), special attention was paid to the presence of silicon. In doing so, good agreement was obtained between AES and XPS measurements.

7. In Y,Ce-TZP ceramics yttrium is the only segregant at low temperatures although the enrichment is less compared to the yttrium enrichment in Y-TZP. At high temperature $\left( \pm 1400^{\circ} \mathrm{C}\right)$ small amounts of Ce segregates.

8. In Ce-TZP, significant segregation is observed at temperatures $\geq 1300^{\circ} \mathrm{C}$. At low temperatures both $\mathrm{Ce}^{3+}$ and $\mathrm{Ce}^{4+}$ ions are present. Although the driving force for segregation of $\mathrm{Ce}^{3+}$ at low temperature is large it does not occur which is probably due to a low mobility.

9. In Y,Ti-TZP ceramics both yttrium and titanium segregate. In these cases all the titanium present at the surfaces seems to be tetravalent.

\section{Acknowledgements}

We thank Philips Components Eindhoven for use of their AES equipment. The Centre for Materials Science (CMO) of the University of Twente is acknowledged for use of their SAM and XPS equipment. This research was partly supported by the Innovative $\mathrm{Re}$ search Program on Technical Ceramics (IOP-TK) with financial aid of the Dutch Ministry of Economic Affairs.

\section{References}

1. R. J. BROOK, in "Treatise of Materials Science and Technology", Vol. 9, edited by F. F. Y. Wang (Academic Press, New York, 1976) p. 331.

2. M. J. VERKERK, A. J. A. WINNUBST and A. J. BURGGRAAF, J. Mater. Sci., 17 (1982) 3113.

3. A. J. A. WINNUBST, P. J. M. KROOT and A. J. BURGGRAAF, J. Phys. Chem. Solids 44 (1983) 955.

4. A. J.A. WINNUBST, A. J. BURGGRAAF in "Advances in Ceramics, Vol. 24A: Science and Technology of Zirconia III" edited by S. Somiya, N. Yamamoto and H. Yanagida (The American Ceramic Society, Inc., Columbus, Ohio, 1988) p. 39.

5. W. C. MACKRODT and P. W. TASKER, J. Am. Ceram. Soc., 72 (1989) 1576.

6. J. NOWOTNY, in "Surfaces and interfaces of ceramic materials" edited by L-C. Dufour, C. Monty and G. Petot-Ervas (Kluwer Academic Publishers, Deventer, 1989) p. 205.

7. A. J. BURGGRAAF, A. J. A. WINNUBST, in "Surface and near-surface chemistry of oxide materials", edited by J. Nowotny and L-C. Dufour (Elsevier Science Publishing B. V., Amsterdam, 1988) p. 449.

8. D. MCLEAN, in "Grain boundaries in metals" (Clarendon Press, Oxford, 1957).

9. E. D. HONDROS and M. P. SEAH, Int. Met. Rev., 222 (1977) 262.

10. R. D. SHANNON and C. T. PREWITT, Acta Cryst., B25 (1969) 925.

11. N. C. WAITE and R. G. FAULKNER, J. Mater. Sci., 25 (1990) 649.

12. G. S. A. M. THEUNISSEN, A. J. A. WINNUBST and A. J. BuRggraAf, J. Am. Ceram. Soc., submitted

13. G. S. A. M. THEUNISSEN, A. J. A. WINNUBST and A. J. BURGgRAAF, J. Eur. Ceram. Soc., submitted

14. W. F. M. GROOT ZEVERT, A. J. A. WINNUBST, G. S. A. M. THEUNISSEN and A. J. BURGGRAAF, $J$. Mater. Sci., 25 (1990) 3449

15. M. A. C. G. VAN DE GRAAF, J. H. H. TER MAAT and A. J. BURGGRAAF, J. Mater. Sci., 20 (1985) 1407

16. P. W. PALMBERG, G. E. RIACK, R. E. WEBER and N. C McDONALD, in "Handbook of Auger Spectroscopy" (Physical Electronics, Edina, Minnesota, 1972).

17. G. S. A. M. THEUNISSEN, A. J. A. WINNUBST and A.J BURGGRAAF, J. Mater. Sci. Lett., 8 (1989) 55.

18. A. J. A. WINNUBST, PhD thesis, University of Twente, Enschede, The Netherlands, (1984). 
19. A. E. HUGHES and B. A. SEXTON, J. Mater. Sci., 24 (1989) 1057.

20. P. SHER WOOD, in "Practical surface analysis by Auger and X-ray photoelectron spectroscopy", edited by D. Briggs and M. P. Seah (Wiley and Sons, New York, 1983) p. 170.

21. C. D. WAGNER, W. M. RIGGS, L. E. DAVIS, J. F. MOULDER and G. E. MUILENBERG, in "Handbook of X-ray Photoelectron Spectroscopy" (Perkin-Elmer Corporation, Minnesota, 1979).

22. D. BRIGGS and J. C. RIVIERE, in "Practical surface analysis by Auger and X-ray photoelectron spectroscopy", edited by D. Briggs and M. P. Seah (John Wiley and Sons, New York, 1983) p. 87.

23. B. A. VAN HASSEL, PhD thesis, University of Twente, Enschede, The Netherlands (1990).

24. B. C. H. STEELE and E. P. BUTLER, in "British Ceramic Proceedings, 1985" (The Institute of Ceramies, Stoke-onTrent, 1985) p. 45

25. A. J. BURGGRAAF, M. VAN HEMERT, D. SCHOLTEN and A. J. A. WINNUBST, in "Reactivity of Solids" (Elsevier Science Publishers B. V., Amsterdam, 1985) p. 797.

26. V. S. STUBICAN and J. R. HELLMANN, in "Advances in Ceramics, Vol. 3, Science and Technology of Zirconia", edited L. Hobbs and A. Heuer (The American Ceramic Society, Inc., Columbus, Ohio, 1981) p. 25.

27. N. KHAN, C. A. LEACH, B. C. H. STEELE, in "Euro Ceramics, Vol. 2: Properties of ceramics", edited by G. de
With, R. A. Terpstra and R. Metselaar (Elsevier Science Publishers Ltd., London, 1989) p. 241.

28. V. LONGo and D. MINiCHeLli, J. Am. Ceram. Soc., 56 (1973) 600.

29. G. PRALINE, B. E. KOEL, R. L. HANCE, H. I. LEE and J. M. WHITE, J. Electron Spectrosc. Relat. Phenon., 21 (1980) 17.

30. L. SCHLAPBACH and J. OSTERWALDER, Solid State Commun., 42 (1982) 271.

31. T. L. BARR, C. G. FRIES, F. CARRIATI, J. C. J. BART and N. GIOR DA NO, $J$. Chem. Soc. Dalton Trans., 1825 (1983)

32. V. I. NEFEDOV, D. GATI and B. F. DZHURINSKII, N. P. SER GUSHIN and Y. V. SALYN, Zh. Neorg. Khim., 20 (1975) 2307.

33. M. T. HERNANDEZ, J. R. JURADO, P. DURAN and J. L. GARCIA-FIER RO, in Proceedings of the 7th CIMTEC conference, 24-30 June, Montecatini Terme 1990, edited by P. Vincenzini (Elsevier Science Publishers B. V., Amsterdam).

34. D. D. SARMA, C. N. R. RAO, J. Electron Spectrosc. Relat. Phenom., 20 (1980) 25.

35. G. S. A. M. THEUNISSEN, PhD thesis, University of Twente, Enschede, The Netherlands, (1991).

Received 25 May

and accepted 27 September 1991 